Article

\title{
Experimental Study and Simulation of the Stress Relaxation Characteristics of Machine-Harvested Seed Cotton
}

\author{
Jun Wang ${ }^{1,2} \mathbb{D}^{\mathbb{D}}$, Hongwen Zhang ${ }^{1,2, * \mathbb{D}}$, Lei Wang ${ }^{1,2}$, Ximei Wei ${ }^{1,2}$, Meng Wang ${ }^{1,2}$, Yanqing Gu ${ }^{1,2}$ and \\ Yunxiao Cai 1,2 \\ 1 College of Mechanical and Electrical Engineering, Shihezi University, Shihezi 832003, China; \\ wj20192009004@163.com (J.W.); wl_mac@shzu.edu.cn (L.W.); 20202009018@stu.shzu.edu.cn (X.W.); \\ 16185@sina.com (M.W.); guyanqing163@163.com (Y.G.); cyx@stu.shzu.edu.cn (Y.C.) \\ 2 Northwest Key Laboratory of Agricultural Equipment, Ministry of Agriculture and Rural Affairs, \\ Shihezi 832003, China \\ * Correspondence: Zhw_mac@shzu.edu.cn
}

Citation: Wang, J.; Zhang, H.; Wang, L.; Wei, X.; Wang, M.; Gu, Y.; Cai, Y. Experimental Study and Simulation of the Stress Relaxation Characteristics of Machine-Harvested Seed Cotton. Appl. Sci. 2021, 11, 9959. https://doi.org/ 10.3390/app11219959

Academic Editor: Ana M. Cavaco

Received: 13 September 2021

Accepted: 15 October 2021

Published: 25 October 2021

Publisher's Note: MDPI stays neutral with regard to jurisdictional claims in published maps and institutional affiliations.

Copyright: (c) 2021 by the authors. Licensee MDPI, Basel, Switzerland. This article is an open access article distributed under the terms and conditions of the Creative Commons Attribution (CC BY) license (https:// creativecommons.org/licenses/by/ $4.0 /)$.

\begin{abstract}
Seed cotton compression molding solves the inconvenience of seed cotton transportation and storage after mechanical harvesting. Stress relaxation is closely related to the performance of the compressed seed cotton. In this study, an electronic universal testing machine with a homemade compression device was used to study the stress relaxation characteristics of machine-harvested seed cotton. The stress relaxation model of machine-harvested seed cotton was established, the influence of test factors on the response indexes was analyzed and, finally, stress relaxation characteristics of machine-harvested seed cotton were simulated. Results show that machine-harvested seed cotton stress relaxation characteristics can be described by the five-element Maxwell model. The equilibrium elastic modulus is negatively correlated with moisture content and cross-section dimensions, and the equilibrium elastic modulus is positively correlated with trash content and compression density. The rapid decay time and the residual stress ratio are negatively correlated with moisture content and compression density, but the influence of trash content and cross-section dimensions are limited. The stress relaxation process of machine-harvested seed cotton was simulated using virtual prototype technology, and the maximum error between the experimental and simulated values was obtained as $4.96 \%$. The feasibility of the virtual prototype technique for the viscoelastic simulation of biomaterials was demonstrated.
\end{abstract}

Keywords: stress relaxation; machine-harvested seed cotton; rheological properties; experiment; mathematical models; simulation of virtual prototype

\section{Introduction}

Cotton, flax and hemp plants are the main textile materials in the world [1]. While cotton is not only an important material, it is also one of the most important economic crops in Xinjiang, China, where the main planting of cotton is upland cotton [2,3]. Its planting area and output have ranked first in China for many years [4]. With the development of agricultural mechanization, cotton's mechanized harvesting has become a trend [5]. Cotton harvested by cotton pickers is collectively referred to as machine-harvested seed cotton, which has a small bulk density and belongs to a loose agricultural fiber material [6]. However, because the integration rate of cotton pickers in China is low, machine-harvested seed cotton requires secondary processing, resulting in its expensive costs of storage and transportation $[7,8]$. Therefore, machine-harvested seed cotton is compressed into modules of certain shapes, sizes, and densities before storing and transporting them [9]. Advanced cotton pickers have integrated compression molding equipment with cotton pickers, which can make mechanical harvest and compression molding continuous, solving the problems effectively $[10,11]$. 
At present, the compression and stress relaxation characteristics of fiber materials have been more widely examined [12]. The compression characteristics of cotton fibers and lint have been studied, while the relationship between compression density and compression force and compression modulus during compression has been derived, and the characteristics of each process has been described [13-18]. A finite element model of the cotton fiber was developed and the stress changes during compression of the cotton fiber were simulated [19]. However, the research on seed cotton compression and stress relaxation is at the initial stage. Hardin studied the compression and creep of seed cotton at small compression densities and established a creep model for seed cotton compression [20-22]; Kong Ft studied the effect of moisture content and feeding quality on the compression characteristics of seed cotton and established a stress relaxation model for seed cotton $[23,24]$. Husin concluded that the cottonseeds breaking rate has increased significantly when the compression density was greater than $400 \mathrm{~kg} / \mathrm{m}^{3}$ [25]. And now research on the stress relaxation characteristics of common agricultural fiber materials has matured. The compression, stress relaxation and creep of the material have been investigated, and rheological models have been developed to analyze the effects of moisture content and compression force on their rheological properties [26-30]. Rheological properties of the agricultural material have also been studied in terms of material type, initial density, compression speed and cross-sectional dimensions, which could provide implications for the successful development of this study [31-37]. The lack of understanding on stress relaxation characteristics of seed cotton restricted us from revealing the compression molding mechanism.

In previous studies on the factors influencing the compression and stress relaxation characteristics of seed cotton, the effects of seed cotton as a mixture and the physical properties of seed cotton on compression and stress relaxation parameters were ignored. In this paper, we investigated the effect of moisture content, trash content, compression density and cross-sectional dimensions on the stress relaxation characteristics of machineharvested seed cotton through stress relaxation tests during the harvest period.

\section{Materials and Methods}

\subsection{Test Materials and Devices}

Machine-harvested seed cotton is a mixed fiber material with a wide range of constituents as one of its main characteristics. In this paper, the main planted machineharvested cotton variety Huiyuan 720 in the Shihezi region was used as the research object, taken from the experimental field of Shihezi University, as shown in Figure 1. It was harvested by a John Deere 7660 cotton picker on 10 October 2020, brought back to the laboratory, dried naturally for one month, and then measured for its bulk density, which was $40 \sim 50 \mathrm{~kg} / \mathrm{m}^{3}$.

Test equipment: Changchun Testing Machine Research Institute CSS-44300 electronic universal material testing machine, Germany Sartorius MA 100 rapid moisture meter, SPS402F precision electronic balance, steel plate ruler, and self-made compression device. The self-made compression device includes a compression chamber with a circular crosssectional shape, an inner diameter of 100, 150, and $200 \mathrm{~mm}$ a height of $270 \mathrm{~mm}$, the compression piston with a radius of $49.5,74.5$, and $99.5 \mathrm{~mm}$, and the demold device. 


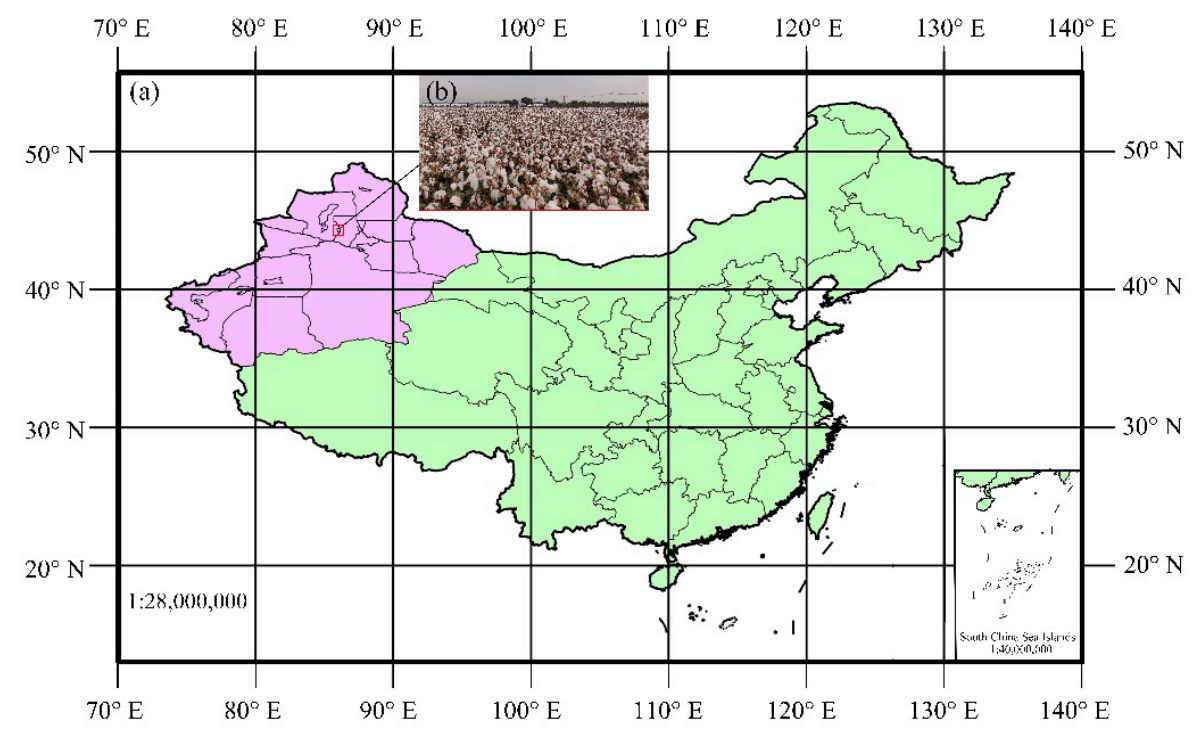

Figure 1. The situation of the experiment filed. (a) the specific geographical location of the experimental field, in which is $88.99^{\circ} \mathrm{E}, 44.31^{\circ} \mathrm{N}$; (b) Experimental cotton field.

\subsection{Experimental Method}

\subsubsection{Experimental Factors}

Cotton harvesting in Xinjiang is concentrated from mid-September to early November every year, and the seed cotton moisture content and trash content are often affected by the working conditions of cotton pickers during harvesting, which are random and highly variable [38-40], while the compression density and cross-sectional dimensions are usually correlated with compression power consumption. Therefore, the stress relaxation characteristics of seed cotton were investigated by using seed cotton moisture content, trash content, compression density, and cross-section dimensions as test factors. The moisture content of seed cotton is generally $6 \sim 22 \%$, and the trash content is $8 \sim 16 \%$ during the harvest period. Meanwhile, when seed cotton is compressed to $400 \mathrm{~kg} / \mathrm{m}^{3}$, the cottonseeds are broken violently, while the seed cotton compression equipment can compress the seed cotton to $200 \mathrm{~kg} / \mathrm{m}^{3}[8,25]$. The cross-sectional shape is selected as circular. The moisture content of machine-harvested seed cotton was selected as $6 \%, 10 \%, 14 \%, 18 \%$ and $22 \%$; trash content was $8 \%, 10 \%, 12 \%, 14 \%$ and $16 \%$; compression density was $200 \mathrm{~kg} / \mathrm{m}^{3}$, $250 \mathrm{~kg} / \mathrm{m}^{3}, 300 \mathrm{~kg} / \mathrm{m}^{3}, 350 \mathrm{~kg} / \mathrm{m}^{3}$, and $400 \mathrm{~kg} / \mathrm{m}^{3}$; the cross-section dimensions of the compression chamber was selected as $100 \mathrm{~mm}, 150 \mathrm{~mm}$ and $200 \mathrm{~mm}$. And the levels of experimental factors are shown in Table 1.

Table 1. The levels of experimental factors.

\begin{tabular}{|c|c|c|c|c|}
\hline Levels & $\begin{array}{c}\text { Compression } \\
\text { Density }\left(\mathrm{kg} \cdot \mathrm{m}^{-3}\right)\end{array}$ & $\begin{array}{c}\text { Moisture } \\
\text { Content (\%) }\end{array}$ & $\begin{array}{c}\text { Trash Content } \\
(\%)\end{array}$ & $\begin{array}{c}\text { Cross-Sectional } \\
\text { Dimension }(\mathrm{mm})\end{array}$ \\
\hline 1 & 200 & 6 & 8 & 100 \\
\hline 2 & 250 & 10 & 10 & 150 \\
\hline 3 & 300 & 14 & 12 & 200 \\
\hline 4 & 350 & 18 & 14 & \\
\hline 5 & 400 & 22 & 16 & \\
\hline
\end{tabular}

\subsubsection{Specimen Preparation}

The experiment procedures are shown in Figure 2. The average moisture content of seed cotton specimens was $4.7 \%$ the trash content was $11.62 \%$, and the moisture content and trash content were adjusted to the desired level using the rehydration method according to Equation (1) [41]. To ensure the uniformity of the trash content, impurities of the corresponding proportional mass were added or removed; the moisture content was added 
to water at the desired level, placed into sealed bags, and stored in the laboratory for more than $48 \mathrm{~h}$.

$$
m_{d}=m_{o} \times \frac{\left|d_{1}-d_{0}\right|}{1-d_{1}},
$$

where

$m_{d}=$ the added (remove) impurities (water) mass (g)

$m_{0}=$ the required modulation specimen mass $(\mathrm{g})$

$d_{0}=$ the trash (moisture) content of specimen $(\%)$

$d_{1}=$ the specimen required to adjust the trash (moisture) content of specimen (\%).

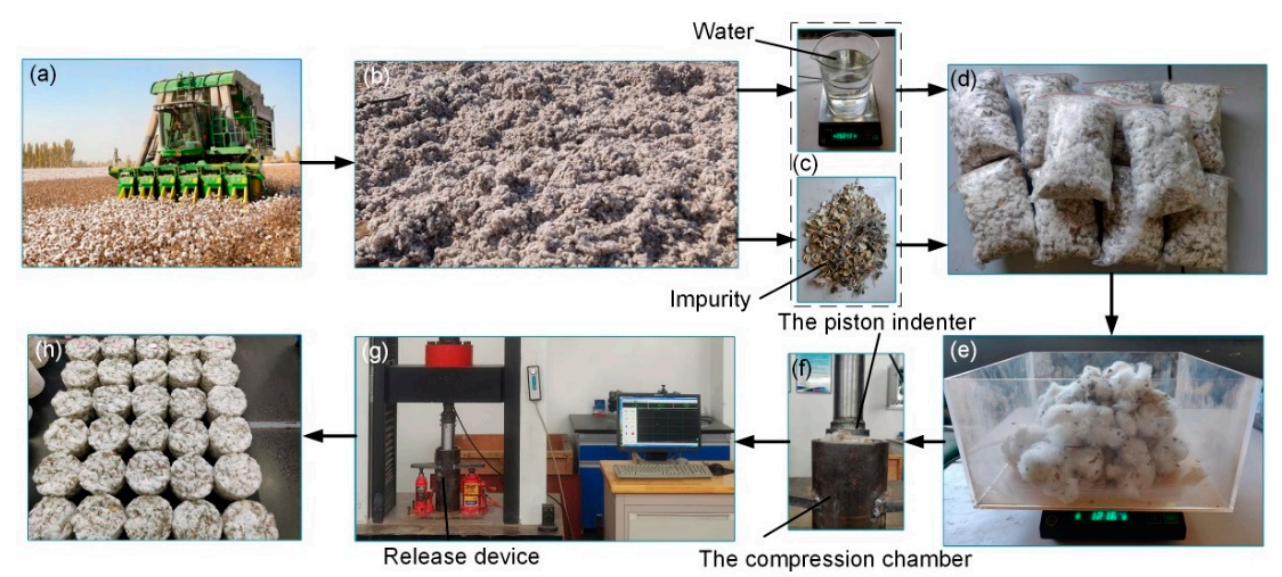

Figure 2. The experiment procedures. (a) mechanized harvesting; (b) machine-harvested seed cotton sampling; (c) rehydration (adding impurities) treatment machine-harvested seed cotton samples; (d) processed samples; (e) feeding quality control; (f) guarantee of initial density; (g) machine-harvested seed cotton compresses and strain remains $300 \mathrm{~s}$; (h) machine-harvested seed cotton molding.

\subsubsection{Compression Data Acquisition of Machine-Harvested Seed Cotton}

Before the test, specimens were taken out in advance and placed in the test environment for more than three hours. Specimens were weighed and placed into the compression device naturally, to ensure the feeding density of $40 \mathrm{~kg} / \mathrm{m}^{3}$, using an electronic material universal testing machine with a $50 \mathrm{~mm} / \mathrm{min}$ compression speed to compress the seed cotton to the target compression density. The compression displacement was calculated according to Formula (2), and the compression displacement and compression speed were set before the test. After the test, the machine-harvested seed cotton that had been compressed were stored, and each group of tests was repeated three times.

$$
l=l_{0}-\frac{\rho_{0} \times l_{0}}{\rho},
$$

where

$l=$ the compression amount of machine-harvested seed cotton $(\mathrm{mm})$

$l_{0}=$ the initial height of machine-harvested seed cotton $(\mathrm{mm})$

$\rho_{0}=$ the initial density of machine-harvested seed cotton $\left(\mathrm{kg} / \mathrm{m}^{3}\right)$

$\rho=$ the compression density during compression $\left(\mathrm{kg} / \mathrm{m}^{3}\right)$.

\section{Results and Discussion}

\subsection{Stress Relaxation Model for the Compression of Machine-Harvested Seed Cotton}

Machine-harvested seed cotton is a common agricultural fiber material, and for the rheological properties of agricultural fiber material, scholars often use the Maxwell and Burgers models. Many studies have also shown that the Maxwell model can better describe the stress relaxation of agricultural materials. Therefore, in this study, the Maxwell model was chosen to characterize the stress relaxation properties of machine-harvested cotton 
by comparing the obtained stress relaxation curves with common viscoelastic models. Although the Maxwell model can describe the stress relaxation process of machine-harvested cotton, the more Maxwell cells, the closer it is to the actual stress relaxation process of the material; it will introduce many variables, which is not conducive to the further solution of the model. And the stress rapid decay time $T_{1}$ is the time required for the stress to decrease to 1/e of the initial stress. The generalized Maxwell has multiple stress relaxation times that are equal to the time required for each Maxwell element to decrease to 1/e of their respective initial stresses. More importantly, due to the special nature of the Maxwell cells (which consists of a spring and a viscous pot), the initial stress on it does not eventually decay to zero, but to a stable value, which we call the equilibrium stress (or modulus).

The stress relaxation of machine-harvested seed cotton with $6 \%$ moisture content, $12 \%$ trash content and $300 \mathrm{~kg} / \mathrm{m}^{3}$ compression density were used as an example, and the stress variation curve of machine-harvested seed cotton with time is plotted when its strain remains $300 \mathrm{~s}$. Using Origin 2017 to fit the regression to it using the Maxwell model and generalized Maxwell model, we can obtain the expression of stress relaxation characteristics of machine-harvested seed cotton, which can be used in 2 Maxwell cells and 1 equivalent spring parallel five-element model [23], as shown in Figure 3a, and the expression is shown in Equation (3).

$$
E(t)=E_{1} e^{-t / T_{s 1}}+E_{2} e^{-t / T_{s 2}}+E_{e}
$$

where

$T_{\mathrm{S} 1}=\eta_{1} / E_{1} ; T_{\mathrm{S} 2}=\eta_{2} / E_{2}$.

$T_{\mathrm{S} 1}, T_{\mathrm{S} 2}=$ the rapid decay time of the stress, the slow decay time of the stress (s)

$E_{1}, E_{2}=$ the modulus of elasticity for the first Maxwell model, the modulus of elasticity for the second Maxwell model (MPa)

$E_{e}=$ the equilibrium elastic modulus $(\mathrm{MPa})$

$\eta_{1}, \eta_{2}=$ the coefficients of viscosity for the first Maxwell model, the coefficients of viscosity for the second Maxwell model (MPa-s).

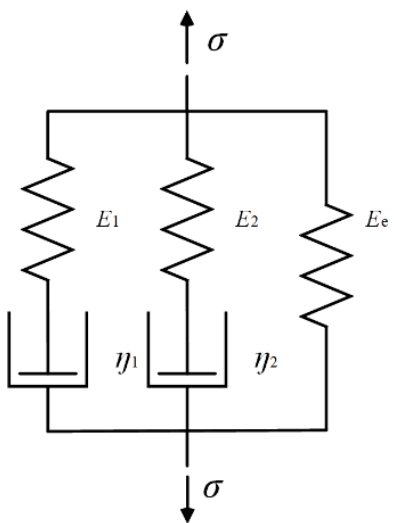

(a)

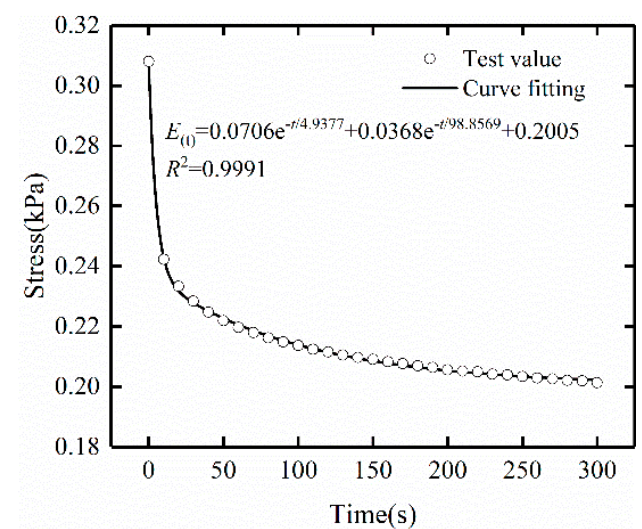

(b)

Figure 3. Stress relaxation model and fitting curve. (a) five-element Maxwell mode; (b) stress relaxation of machine-harvested cotton fitting curve.

The compression process of machine-harvested seed cotton is divided into two stages. The first stage is the compression, where with increasing compression displacement the compression density of machine-harvested seed cotton increases continuously; the second stage is the stress relaxation stage, in which the stress change in this stage also has two stages. In the initial of stress relaxation, stress decays rapidly to $1 /$ e of the initial, which occurs within $10 \mathrm{~s}$ of stress relaxation; after that the stress decreases slowly and its value tends to a constant value. The proper equation is shown in Equation (4).

$$
E(t)=0.0706 \mathrm{e}^{-t / 4.9377}+0.0368 \mathrm{e}^{-t / 98.8569}+0.2005,
$$


From Equation (4) and Figure 3b, the stress rapid decay time is $4.9377 \mathrm{~s}$, the stress slow decay time is $98.8569 \mathrm{~s}$, the equilibrium elastic modulus is $0.2005 \mathrm{MPa}$, and the fitted coefficient of determination $R^{2}>0.99$, indicating that the equation can better reflect the stress relaxation in the stress relaxation phase of machine harvested seed cotton.

\subsection{Stress Relaxation Characteristics of Machine-Harvested Seed Cotton}

$T_{1}$ reflects the rapid decay rate of stress relaxation; The smaller $T_{1}$ is, the faster the stress decay of machine-harvested seed cotton changes. $T_{1}$ determines the optimal length of wrapping and winding time of machine-harvested seed cotton after baling [25]; $E_{e}$ reflects the ability of machine-harvested seed cotton to recover in the process of stress relaxation; the smaller $E_{e}$ is, the less loose wrapping and damage phenomenon of the machine-harvested seed cotton can be reduced after wrapping. $\varepsilon$ reflects the residual stress ratio of machine-harvested seed cotton after stress relaxation, similar to $E_{e}$, which indicates the stress relaxation of machine-harvested seed cotton. The smaller $\varepsilon$ is, the more it can be used to measure the effect of stress relaxation, and its calculation formula is shown in Equation (5):

$$
\varepsilon=\frac{\sigma_{\mathrm{s}}}{\sigma_{0}} \times 100
$$

where

$$
\begin{aligned}
& \sigma_{s}=\text { the stress after relaxation stabilization (MPa) } \\
& \sigma_{0}=\text { the stress after reaching the set strain (MPa) } \\
& \varepsilon=\text { the residual stress ratio (\%). }
\end{aligned}
$$

To reveal the effect of moisture content, trash content, compression density, and crosssectional dimensions of machine-harvested seed cotton on stress relaxation characteristic parameters, the five-element Maxwell model was used to fit all stress relaxation curves of machine-harvested seed cotton, and the stress relaxation characteristic parameters were obtained, taking the average of the three groups of experiments, as shown in Table 2. A

\begin{tabular}{|c|c|c|c|c|c|c|c|c|c|c|}
\hline Factors & Levels & $\begin{array}{c}E_{1} \\
(\mathrm{MPa})\end{array}$ & $\begin{array}{c}E_{2} \\
(\mathrm{MPa})\end{array}$ & $\begin{array}{c}E_{e} \\
(\mathrm{MPa})\end{array}$ & $\begin{array}{c}\eta_{1} \\
\text { (MPa.s) }\end{array}$ & $\begin{array}{c}y_{2} \\
\text { (MPa.s) }\end{array}$ & $T_{1}(\mathrm{~s})$ & $T_{2}(\mathrm{~s})$ & $\mathcal{\varepsilon}(\%)$ & $R^{2}$ \\
\hline \multirow{5}{*}{$\begin{array}{c}\text { Moisture } \\
\text { content (\%) }\end{array}$} & 6 & 0.0735 & 0.0378 & 0.1296 & 0.379 & 3.795 & 5.158 & 100.410 & 54.168 & 0.999 \\
\hline & 10 & 0.0602 & 0.0317 & 0.1099 & 0.306 & 3.222 & 5.085 & 101.646 & 53.302 & 0.999 \\
\hline & 14 & 0.0544 & 0.0284 & 0.0876 & 0.278 & 2.831 & 5.102 & 99.669 & 52.085 & 0.999 \\
\hline & 18 & 0.0486 & 0.0249 & 0.0737 & 0.245 & 2.475 & 5.049 & 99.392 & 50.489 & 0.999 \\
\hline & 22 & 0.0395 & 0.0219 & 0.0573 & 0.201 & 2.205 & 5.090 & 100.694 & 48.748 & 0.999 \\
\hline \multirow{5}{*}{$\begin{array}{c}\text { Trash content } \\
(\%)\end{array}$} & 8 & 0.0691 & 0.0352 & 0.1843 & 0.348 & 3.546 & 5.031 & 100.735 & 64.173 & 0.999 \\
\hline & 10 & 0.0696 & 0.0345 & 0.2049 & 0.343 & 3.446 & 4.934 & 99.884 & 66.578 & 0.999 \\
\hline & 12 & 0.0844 & 0.0423 & 0.2055 & 0.412 & 4.231 & 4.884 & 100.035 & 62.207 & 0.999 \\
\hline & 14 & 0.0919 & 0.0458 & 0.2187 & 0.451 & 4.604 & 4.912 & 100.524 & 61.810 & 0.999 \\
\hline & 16 & 0.0868 & 0.0431 & 0.2331 & 0.431 & 4.334 & 4.966 & 100.562 & 64.526 & 0.999 \\
\hline \multirow{5}{*}{$\begin{array}{c}\text { Compression } \\
\text { density } \\
\left(\mathrm{kg} \cdot \mathrm{m}^{-3}\right)\end{array}$} & 200 & 0.0073 & 0.0057 & 0.0396 & 0.045 & 0.631 & 6.202 & 110.678 & 75.684 & 0.997 \\
\hline & 250 & 0.0229 & 0.0165 & 0.0904 & 0.134 & 1.763 & 5.843 & 106.820 & 70.067 & 0.999 \\
\hline & 300 & 0.0634 & 0.0326 & 0.1791 & 0.315 & 3.278 & 4.966 & 100.541 & 65.457 & 0.999 \\
\hline & 350 & 0.1528 & 0.0718 & 0.3887 & 0.738 & 7.073 & 4.830 & 98.511 & 63.651 & 0.999 \\
\hline & 400 & 0.3416 & 0.1528 & 0.7737 & 1.590 & 14.995 & 4.655 & 98.134 & 61.326 & 0.999 \\
\hline \multirow{3}{*}{$\begin{array}{l}\text { Cross-sectional } \\
\text { dimensions } \\
(\mathrm{mm})\end{array}$} & 100 & 0.0394 & 0.0212 & 0.1238 & 0.204 & 2.168 & 5.179 & 102.282 & 67.511 & 0.999 \\
\hline & 150 & 0.0334 & 0.0184 & 0.1046 & 0.173 & 1.822 & 5.167 & 99.032 & 67.106 & 0.999 \\
\hline & 200 & 0.0299 & 0.0160 & 0.0929 & 0.151 & 1.624 & 5.051 & 101.477 & 67.243 & 0.999 \\
\hline
\end{tabular}
correlational analysis of stress relaxation characteristics parameters was conducted, as shown in Table 3.

Table 2. Parameters of stress relaxation of machine-harvested cotton. 
Table 3. Correlation analysis of stress relaxation characteristics parameters.

\begin{tabular}{ccccccccc}
\hline Items & $E_{1}$ & $E_{2}$ & $E_{\mathbf{e}}$ & $\eta_{1}$ & $\eta_{\mathbf{2}}$ & $\boldsymbol{T}_{\mathbf{1}}$ & $\boldsymbol{T}_{\mathbf{2}}$ & $\varepsilon$ \\
\hline Moisture content & $-0.979^{* *}$ & $-0.981^{* *}$ & $-0.992^{* *}$ & $-0.981^{* *}$ & $-0.978^{* *}$ & $-0.672^{* *}$ & -0.332 & $-0.899^{* *}$ \\
Trash content & $0.703^{* *}$ & $0.662^{* *}$ & $0.949^{* *}$ & $0.687^{* *}$ & $0.647^{* *}$ & -0.316 & 0.035 & -0.175 \\
Compression density & $0.913^{* *}$ & $0.920^{* *}$ & $0.929^{* *}$ & $0.918^{* *}$ & $0.920^{* *}$ & $-0.825^{*}$ & $-0.579^{*}$ & $-0.971^{* *}$ \\
Cross-sectional dimensions & $-0.692^{*}$ & $-0.897^{* *}$ & $-0.895^{* *}$ & $-0.817^{* *}$ & $-0.887^{* *}$ & -0.197 & -0.194 & -0.075 \\
\hline
\end{tabular}

Note: ${ }^{* *}$ means extremely significant $(p<0.01) ;{ }^{*}$ means significant $(p<0.05)$.

We fitted the stress relaxation characteristics of machine-harvested seed cotton under different conditions, and the results are shown in Table 2. The fitting coefficient of stress relaxation parameters $R^{2}>0.99$, indicating that the five-element Maxwell model can accurately describe the stress relaxation of machine-harvested seed cotton. Meanwhile, the correlation analysis results in Table 3 show that the equilibrium elastic modulus $E_{e}$ is negatively correlated with moisture content and cross-sectional dimensions $(p<0.01)$, but is positively correlated with trash content and compression density $(p<0.01)$. The rapid decay time $T_{1}$ is negatively correlated with moisture content and compression density $(p<0.05)$, but is weakly correlated with trash content and cross-sectional dimensions. The residual stress ratio is negatively correlated with moisture content and compression density $(p<0.01)$, but is weakly correlated with trash content and Cross-sectional dimensions.

\subsubsection{Effect of Moisture Content on Stress Relaxation Characteristics}

As shown in Figure 4a, as the moisture content increases, a smaller compression force is required when the seed cotton is compressed to the same density [23,32]. The main reason for this phenomenon is that the cotton fiber, cottonseeds, cotton and other components of the water absorption are slightly different, the higher the moisture content of is, the smaller the elastic modulus is would be [25,42]. With the increase of seed cotton moisture content, it is easier for seed cotton to be densely compressed, and it requires less compression force. As shown in Figure $4 \mathrm{~b}, \mathrm{c}$, the minimum value of $T_{1}$ appeared at $18 \%$ with increasing moisture content, and $E_{e}$ and $\varepsilon$ gradually decreased with moisture content increasing. This is due to the fact that the increasing moisture content disrupts the hydrogen bonds in the cell wall, shielding the interaction forces between macromolecules, and increasing intermolecular flexibility [41], thus making it easier to move, requiring less compression force, and the faster the stress relaxation rate, the smaller the residual stress ratio. It shows that seed cotton relaxes better at a high moisture content.

\subsubsection{Effect of Trash Content on Stress Relaxation Characteristics}

The trash content increases the bulk density of machine-harvested seed cotton, while the impurities are rich in the higher modulus of elasticity of wood fibers [42,43]. As shown in Figure 5a, the initial stress of seed cotton gradually increases with the increase of trash content. The main reason for this phenomenon is that the modulus of elasticity of wood fibers such as impurities is large, resulting in the need for a larger compression force for seed cotton at a high trash content [43]. As shown in Figure 5b,c, the $E_{e}$ increases slightly with the trash content, and the main reason is that the compression force increases with the increase of trash content, and there is a certain transient drop under the larger compression force; while $T_{1}$ increases with the decrease of trash content, and the minimum value appears at $12 \%$, which is explained by the proper increase of trash content, which can make the seed cotton and impurities easier to bond, but an excessively high or low trash content will hinder the close combination between seed cotton and the impurities [44]. With the increase of trash content, the $\varepsilon$ shows a fluctuating decrease, and the main reason for this phenomenon is that the trash content of seed cotton is not uniform, and there will be certain pores in the compression process, which makes the $\varepsilon$ decrease with the increase of trash content. 


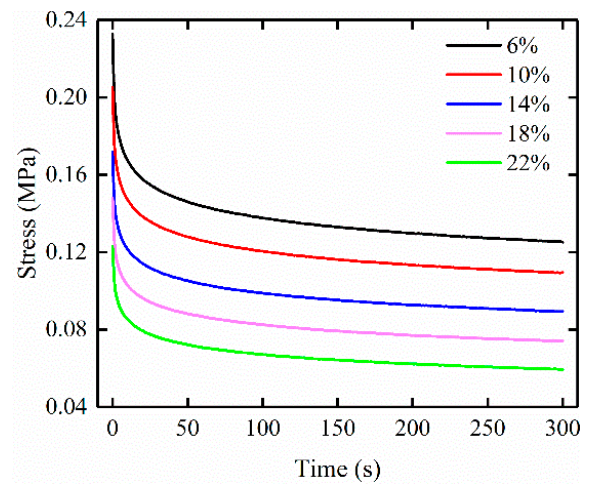

(a)

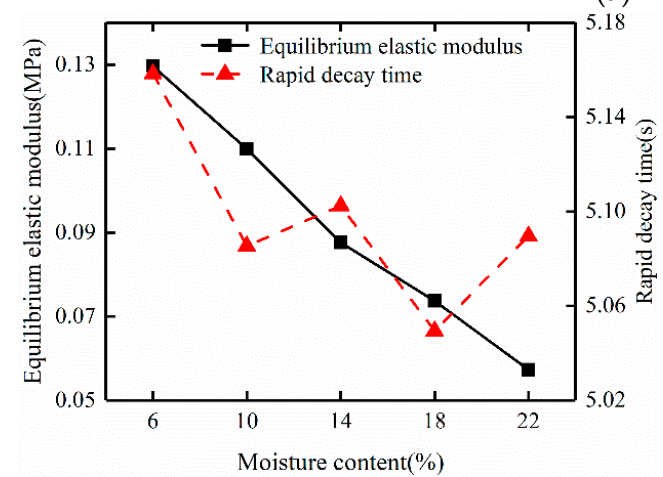

(b)

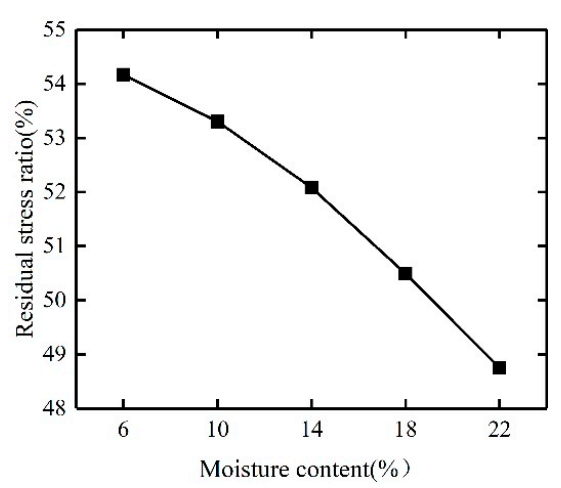

(c)

Figure 4. Stress relaxation characteristics at different moisture contents: (a) Stress relaxation curve; (b) Equilibrium elastic modulus $E_{e}$ and rapid decay time $T_{1}$; (c) Residual stress ratio $\varepsilon$.

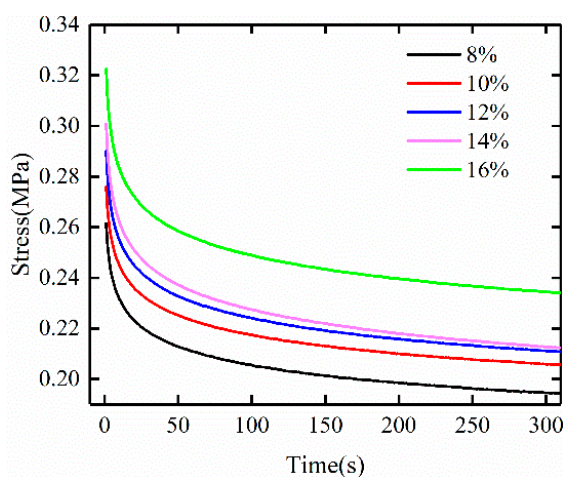

(a)

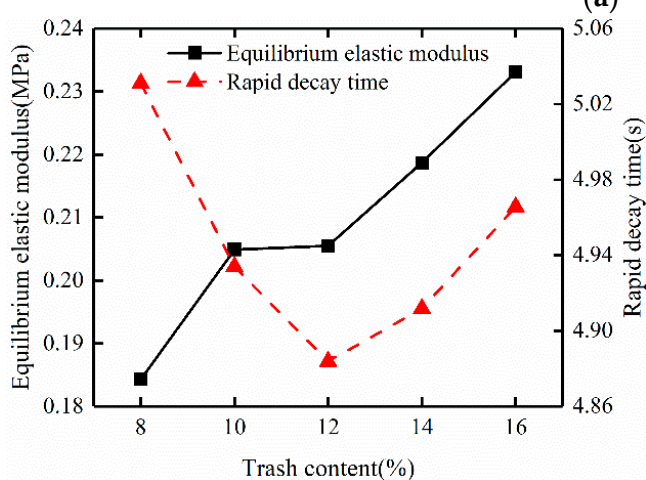

(b)

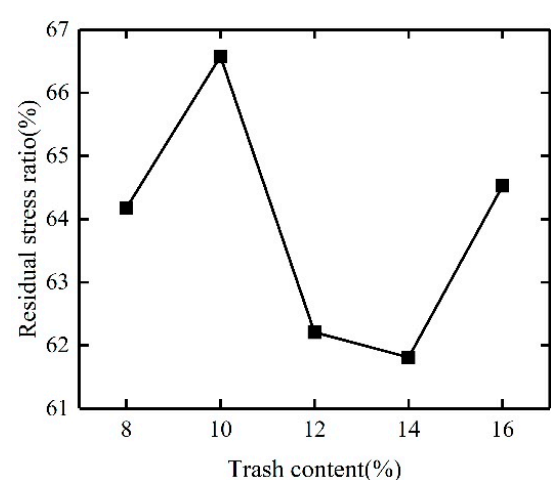

(c)

Figure 5. Stress relaxation characteristics at different trash contents: (a) Stress relaxation curve; (b) Equilibrium elastic modulus $E_{e}$ and rapid decay time $T_{1}$; (c) Residual stress ratio $\varepsilon$. 


\subsubsection{Effect of Compression Density on Stress Relaxation Characteristics}

The high density compression of seed cotton increases the required compression force $[14,17,18,23]$. Figure 6 a shows the stress relaxation characteristics curves of machineharvested seed cotton compressed to different compression densities. The trends of stress relaxation characteristics curves of machine-harvested seed cotton were basically similar at each compression density. Figure $6 b, c$ show the curves of stress relaxation characteristics of parameters $E_{e}, T_{1}$, and $\varepsilon$ with the compression density of machine-harvested seed cotton under different compression densities, $T_{1}$ decreases with the increase of compression density, and the lowest point appears when the compression density is $400 \mathrm{~kg} / \mathrm{m}^{3}$. The main reason is that the compression force of machine-harvested seed cotton at high density is large, and the stress exists transient drop, stress relaxation rate is fast; thus $T_{1}$ has the minimum value $[36,41]$. Moreover, the maximum value of $E_{e}$ and the minimum value of $\varepsilon$ were obtained at the compression density of $400 \mathrm{~kg} / \mathrm{m}^{3}$. This is due to the fact that the higher the compression density is, the higher the compression force and the greater the corresponding stress are $[23,32,35]$, while the stress relaxation process itself is a long process, and the rate of stress decrease becomes slower, in which there is a higher $E_{e}$ at high compression density. Meanwhile, with the increase of compression density, the seed cotton pressure drops, while its equilibrium stress time $T_{2}$ is also larger, which means that the seed cotton under high compression density reaches the equilibrium modulus $E_{e}$ rapidly, and there is more time for stress homogenization, thus there is smaller $\varepsilon$ under high compression density, indicating a better stress relaxation effect.

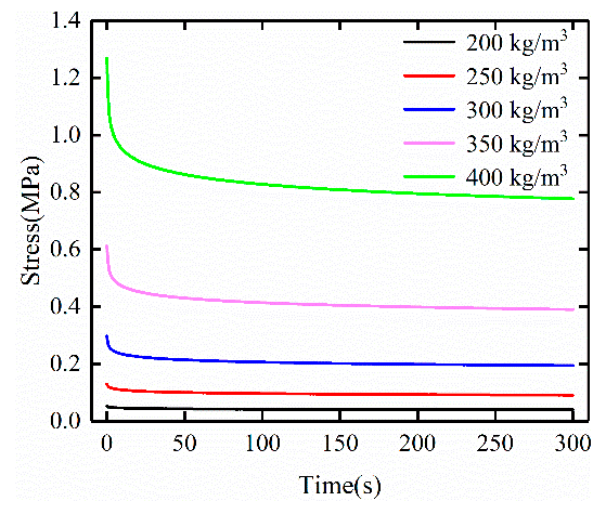

(a)

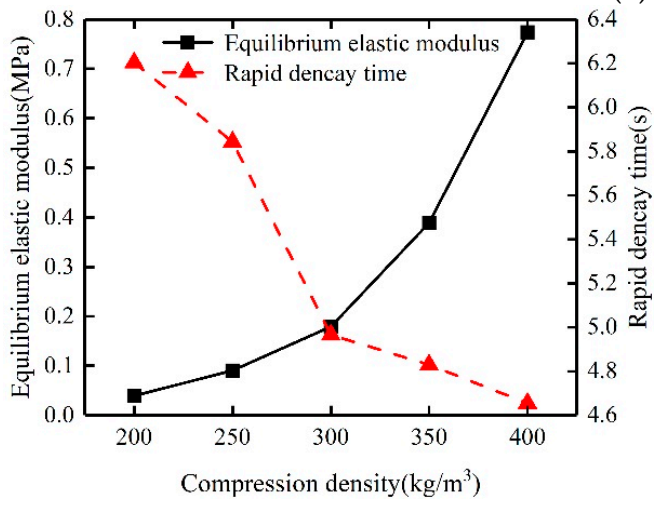

(b)

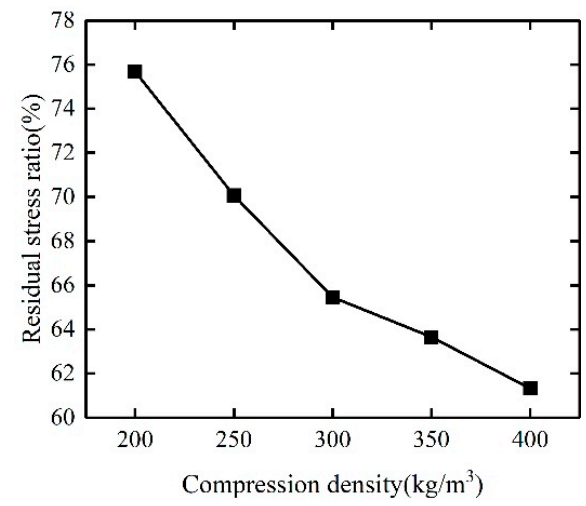

(c)

Figure 6. Stress relaxation characteristics at different compression densities: (a) Stress relaxation curve; (b) Equilibrium elastic modulus $E_{e}$ and rapid decay time $T_{1},(\mathbf{c})$ Residual stress ratio $\varepsilon$. 


\subsubsection{Effect of Section Size on Stress Relaxation Characteristics}

As shown in Figure 7a, the initial stress of seed cotton gradually decreases with the increase of cross-sectional dimensions. When the seed cotton is compressed to the same density, the initial stress gradually decreases with the increase of the cross-sectional dimensions. The stress can be gradually homogenized in the radial direction due to the larger cross-sectional dimensions, which made the compression force required decrease during the compression process [36]. Figure $7 \mathrm{~b}, \mathrm{c}$ show the curves of stress relaxation characteristics of parameters $E_{e}, T_{1}$ and $\varepsilon$ with cross-sectional dimensions of machineharvested seed cotton under different cross-sectional dimensions. $E_{e}$ decreases gradually with the increase of cross-sectional dimensions, and there is a minimum value at of $200 \mathrm{~mm}$. The primary reason is that the compression force decreases with the increase of crosssectional dimensions [45], and the stress is easily homogenized along the direction of crosssectional dimensions. Meanwhile, there is a larger compression force and a certain pressure transient drop at the small cross-sectional dimensions [26], therefore, the equilibrium elastic modulus firstly increases and then decreases with the increase of cross-sectional dimensions. However, the $T_{1}$ decreases slightly with the cross-sectional dimensions, and the decrease is limited, because in larger cross-sectional dimensions, the stress can be fully homogenized along the compression direction and radial direction. With the increase of cross-sectional dimensions, the $\varepsilon$ shows a fluctuating decrease, and the reason for this phenomenon is that the larger the cross-sectional dimensions, the stress rapid decay time is smaller, and the seed cotton has a longer time for stress homogenization.

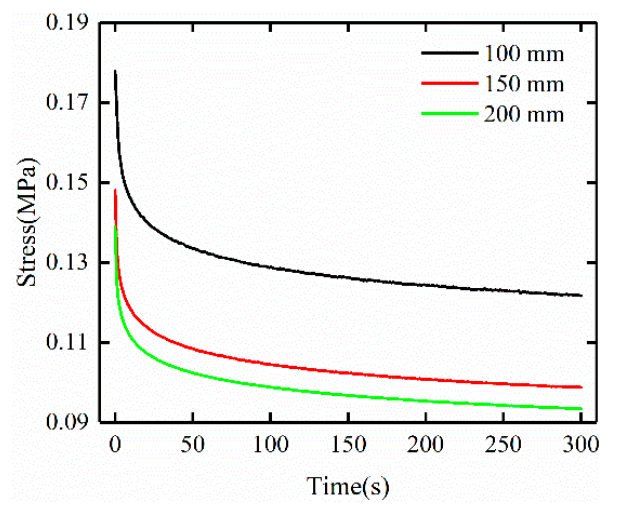

(a)

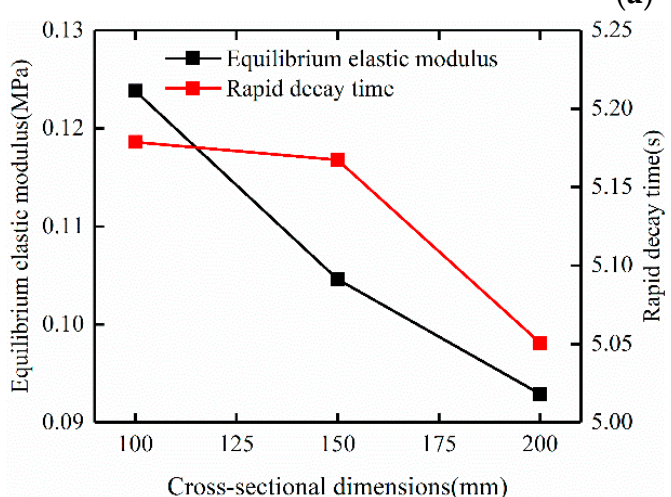

(b)

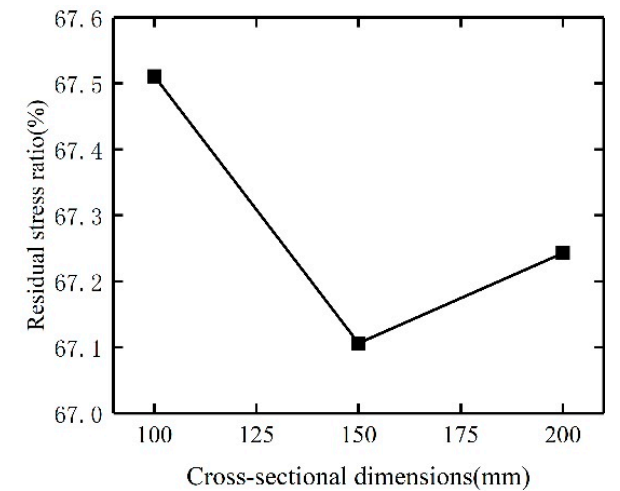

(c)

Figure 7. Stress relaxation characteristics at different cross-sectional dimensions: (a) Stress relaxation curve; (b) Equilibrium elastic modulus $E_{e}$ and rapid decay time $T_{1} ;(\mathbf{c})$ Residual stress ratio $\varepsilon$.

\section{Virtual Simulation of Stress Relaxation of Machine-Harvested Seed Cotton}

Stress relaxation is the relationship between stress and time after the material has been compressed to a constant deformation, in which it can be reduced to a kinetic system and the process can be analyzed using virtual prototyping techniques. Some scholars used this 
method to simulate viscoelastic materials with some success $[46,47]$. Stress relaxation is the relationship between stress and time after the material has been compressed to a constant deformation, so it can be reduced to a kinetic system and the process can be analyzed using virtual prototyping techniques. Some scholars used this method to simulate and analyze viscoelastic materials with some success $[46,47]$. This study uses this method to model and simulate the stress relaxation process of machine-harvested seed cotton in a virtual prototype. The five-element Maxwell model has been obtained in the previous paper to better characterize the stress relaxation process of machine harvested seed cotton, and the stress relaxation model constructed by it can be characterized by two Maxwell units, one equilibrium spring, and a five-element Maxwell model composed of three in parallel, as shown in Figure 3a, while the Maxwell unit can be composed of one Hooke body (spring) and one Newton body (viscous pot) in series, and they can be found in ADAMS with the corresponding actor, spring and damping. Therefore, the corresponding seed cotton stress relaxation model can be established in ADAMS, as shown in Figure 8a.

After the virtual prototype model of stress relaxation of machine harvested seed cotton is established, the corresponding settings and descriptions are made: (1) Because the unit of force in ADAMS simulation analysis is $\mathrm{N}$ and the unit of stress is $\mathrm{N} / \mathrm{mm}^{2}$, the force and stiffness can be used in ADAMS instead of stress and modulus of elasticity;(2) As stress relaxation is the law of change of stress with time at constant strain, independent of weight, the modeling environment is set to a gravity-free state; (3) Stress relaxation also requires constant strain, in which fixed constraints are used to cement upper pressure head, lower pressure head to the earth, and the springs and dampers in the Maxwell cell to movement along the vertical direction of the earth by prismatic pair 4 and 9;(4) The spring element preload in the model is also set to the initial stress of the stress relaxation as the stress values obtained from the aforementioned tests $\left(\sigma_{1}, \sigma_{2}, \sigma_{\mathrm{e}}\right)$.

After the setup is completed, the simulation analysis is conducted and the simulation time is set to $300 \mathrm{~s}$, with a step size of $0.1 \mathrm{~s}$ with regard to the test data to obtain the curve of stress variation with time for the upper baffle [48]. In this section, the simulation test of stress relaxation of machine-harvested seed cotton with a moisture content of $14 \%$ and compression density of $300 \mathrm{~kg} / \mathrm{m}^{3}$ is carried out as an example, and the test results and simulation results are obtained, as shown in Figure $8 \mathrm{~b}$.

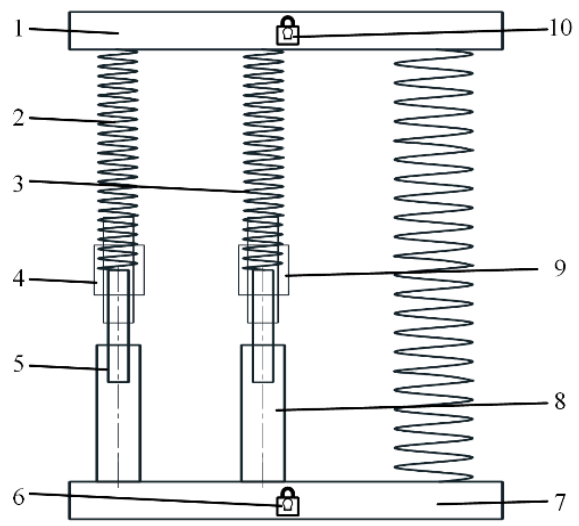

(a)

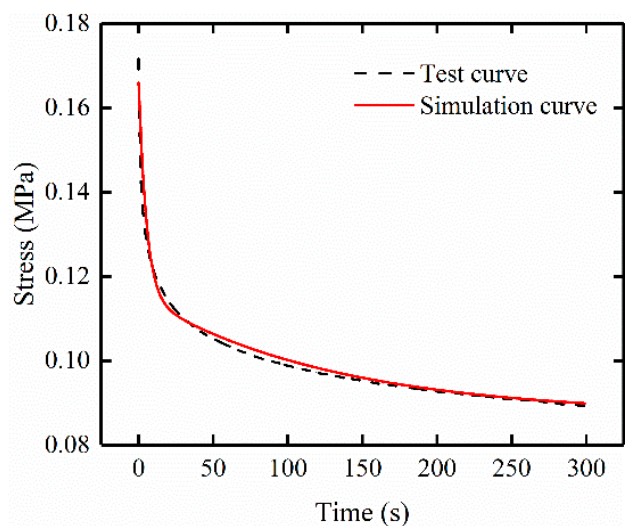

(b)

Figure 8. Stress relaxation virtual prototype model and test results: (a) Model: 1. upper pressure head 2. spring 13 . spring 24 . prismatic pair 15 . damper 16 . fixed constraint 17 . lower pressure head 8. damper 29 . prismatic pair 2 10. fixed constraint 2; (b) Curves comparison between simulation and test results.

The simulation results show that the test and simulation curves are consistent, with a maximum deviation of $4.96 \%$. This shows that it is feasible to use the virtual prototype method to study and analyze the stress relaxation characteristics of seed cotton. And it also shows that the five-element Maxwell model can better describe the stress relaxation 
characteristics of machine-harvested seed cotton. The possible reasons for the errors are: (1) the test of stress relaxation is affected by various uncertainties, which leads to errors caused by inaccurate calculation of model parameters; and (2) the ADAMS simulation, considering that stress relaxation is unrelated to material quality, sets the quality of each component to the minimum amount allowed by the software, which made the simulation results deviate.

\section{Conclusions}

(1) The stress relaxation model of machine-harvested seed cotton can be described by a five-element Maxwell model. The relevant parameters of the stress relaxation model were obtained for different moisture content, trash content, compression density and cross-sectional dimensions, and the $R^{2}>0.99$.

(2) All factors have a certain influence on the stress relaxation characteristics of machine-harvested cotton. Moisture content, cross-sectional dimensions and equilibrium elastic modulus are negatively correlated, while trash content, compression density and equilibrium elastic modulus are positively correlated. Moisture content and compression density are negatively correlated with rapid decay time and residual stress ratio. According to the relationship diagram between factors and response indexes, the fast decay time decreases and then increases with the increase of trash content, and slowly decreases with the cross-sectional dimensions. The residual stress ratio decreases with the trash content fluctuation, but the cross-sectional dimensions have little effect on it.

(3) A rheological model was used to simulate and analyze the stress relaxation process of seed cotton from a kinetic point of view. A stress relaxation intrinsic model based on ADAMS was established to simulate the stress relaxation process of seed cotton and the maximum deviation between the simulated and experimental values was $4.96 \%$, indicating that the virtual prototype can be used to simulate and study the rheological process of seed cotton, thus broadening the research method of biomechanics.

The test results can provide some data and theoretical support for the study of stress relaxation and compression of seed cotton.

Author Contributions: Conceptualization, J.W., X.W. and Y.G.; methodology, H.Z., L.W., M.W. and J.W.; software, J.W., X.W. and Y.C.; validation, H.Z., L.W. and M.W.; formal analysis, H.Z. and J.W.; investigation, J.W., Y.G. and Y.C.; resources, H.Z. and M.W.; data curation, J.W., H.Z. and L.W.; writing-original draft preparation, J.W., X.W. and H.Z.; writing-review and editing, H.Z., L.W. and M.W.; visualization, M.W., L.W. and H.Z.; supervision, H.Z. and L.W.; project administration, H.Z., L.W. and M.W.; funding acquisition, H.Z. and L.W. All authors have read and agreed to the published version of the manuscript.

Funding: This work was financially supported by the Corps Major Scientific and Technological Projects (Grant number: 2018AA008), the Corps Key Field Innovative Team Building Project (Grant number: 2019CB006) and the Autonomous Region Graduate Student Innovation Program (Grant number: XJ2021G114).

Institutional Review Board Statement: Not applicable.

Informed Consent Statement: Not applicable.

Data Availability Statement: All relevant data presented in the article are stored according to institutional requirements and, as such, are not available online. However, all data used in this manuscript can be made available upon request to the authors.

Conflicts of Interest: The authors declare no conflict of interest.

\section{References}

1. Muzyczek, M. The use of flax and hemp for textile applications. In Handbook of Natural Fibres; Woodhead Publishing: Cambridge, UK, 2012; Volume 2, pp. 312-328.

2. Wang, L.; Wen, Y. Problems in Cotton Planting Varieties and the Countermeasures in Xinjiang. China Cotton 2015, 42, 4-8. [CrossRef] 
3. Wang, Y.; Chen, M.; Liang, F.; Tian, J.; Zhang, W. Photosynthates competition within the boll-leaf system is alleviated with the improvement of photosynthetic performance during the succession of Xinjiang cotton cultivars. Ind. Crops Prod. 2020, 160, 113121-113127. [CrossRef]

4. Lu, X.R.; Jia, X.Y.; Niu, J.H. The Present Situation and Prospects of Cotton Industry Development in China. Sci. Agric. Sin. 2018, 51, 26-36. [CrossRef]

5. Meng, Y.; Song, J.; Lan, Y.; Mei, G.; Han, Y. Harvest aids efficacy applied by unmanned aerial vehicles on cotton crop. Ind. Crops Prod. 2019, 140, 111645-111654. [CrossRef]

6. Zhang, L.; Zhou, X.; Jiang, Z.C.; Jiang, Y.X.; Liu, X.F. Research on the current situation and development of full mechanization of cotton. Hebei Farm. Mach. 2021, 9, 26-27. [CrossRef]

7. Zou, Z.H. A brief discussion on the development of machine picking cotton in Xinjiang corps. China Fiber Insp. $2020,5,33$.

8. Chen, X.G.; Wen, H.J.; Zhang, W.R.; Pan, F.C.; Zhao, Y. Advances and progress of agricultural machinery and sensing technology fusion. Smart. Agric. 2020, 2, 1-16.

9. Van der Sluijs, M.H.; Long, R.L.; Bange, M.P. Comparing cotton fiber quality from conventional and round module harvesting methods. Text. Res. J. 2015, 85, 987-997. [CrossRef]

10. Wang, L.L.; Guo, J.; Sun, F.X.; Gao, A.D.; Shao, Y.W. Introduction of airborne baler for self-propelled domestic cotton picker. Xinjiang Farm Res. Sci. Technol. 2015, 38, 36-37. [CrossRef]

11. Li, J.X.; Liu, J.M. Storage and processing of machine-picked cotton (I). China Cotton Process. 2011, 3, 36-38. [CrossRef]

12. Wang, R.L.; Wei, K.F.; Liu, Y.; Chen, Z.Y.; Ma, F.; Liu, D.J. Optimization of process parameters for multi-frequency rapid compression molding of corn stalk silk used for forage. Trans. Chin. Soc. Agric. Eng. 2016, 32, 277-281. [CrossRef]

13. Zhang, J.; Tian, L.; Ji, C.; Wu, J. Study status of agricultural materials compressing technology. J. Chin. Agric. Mech. 2019, 40, 93-102. [CrossRef]

14. Wang, Z.C. A comparison of US and Soviet cotton compression property equations. China Cotton Process. 1994, 3, $26-27$.

15. Jing, H.; YU, W.D. Estimation of fiber orientation and length distribution in cashmere fibrous assemblies. Text. Res. J. 2019, 89, 1084-1093. [CrossRef]

16. Li, Y.; Zhang, H.; Zhang, Y.Q.; Chen, X.C.; Liu, W.L. Research on compressive force transmission properties and densitiesmechanical properties model of cotton fiber assembly. J. Text. Res. 2016, 37, 19-25. [CrossRef]

17. Li, Y.; Li, J.; Wu, B.; Hu, S.M.; Chen, X.C. Analysis and research on the principle of compressive force transmission of cotton fiber assembly. Shanghai Text. Sci. Technol. 2019, 47, 8-11.

18. Kelly, P.A. A viscoelastic model for the compaction of fibrous materials. J. Text. Inst. Proc. Abstr. 2011, 102, 689-699. [CrossRef]

19. Xu, M.J.; Chen, X.C.; Wang, J.; Li, Y. Finite element analysis modeling research on the compression process of cotton fiber assembly. Text. Res. J. 2020, 90, 1414-1427. [CrossRef]

20. Hardin, R.; Searcy, S. Viscoelastic properties of seed cotton. Trans. ASABE 2008, 51, 803-810. [CrossRef]

21. Hardin, R.; Searcy, S. Modeling of seed cotton viscoelastic properties. Trans. ASABE 2009, 52, 707-714. [CrossRef]

22. Hardin, R. Viscoelastic Properties of Seed Cotton and Their Effect on Module Shape and Density. Master's Thesis, Texas A \& M University, College Station, TX, USA, August 2004.

23. Kong, F.T.; Wu, T.; Chen, C.L.; Sun, Y.F.; Xie, Q.; Shi, L. Mechanical properties and construction of constitutive model for compression and stress relaxation of seed cotton. Trans. Chin. Soc. Agric. Eng. 2021, 37, 53-60. [CrossRef]

24. Kong, F.T.; Shi, L.; Zhang, Y.T.; Chen, C.L.; Sun, Y.F.; Xie, Q.; Huang, M.S. Simulation and Analysis on Compression Effect of Screw Conveyor in the Hopper on Seed Cotton. J. Agric. Mech. Res. 2017, 39, 77-81.

25. Husin, N.A.B. Impact of Seed Cotton Compression on Cottonseed Quality. Master's Thesis, Texas A \& M University, College Station, TX, USA, May 2016.

26. Du, X.X.; Wang, C.G.; Guo, W.B.; Wang, H.B.; Jin, M.; Liu, X.D.; Li, J. Stress Relaxation Characteristics and Influencing Factors of Sweet Sorghum: Experimental Study. BioResources 2018, 13, 8761-8774. [CrossRef]

27. Jia, H.L.; Chen, T.Y.; Zhang, S.W.; Sun, X.M.; Yuan, H.F. Effects of pressure maintenance and strain maintenance during compression on subsequent dimensional stability and density after relaxation of blocks of chopped corn straw. BioResources $\mathbf{2 0 2 0}$ 15, 3717-3736. [CrossRef]

28. Chen, T.Y.; Jia, H.L.; Li, M.W.; Zhao, J.L.; Deng, J.Y.; Fu, J.; Yuan, H.F. Mechanism of restraining maize stalk block springback under pressure maintenance/strain maintenance. Trans. Chin. Soc. Agric. Eng. 2021, 37, 51-58. [CrossRef]

29. Kemmerer, B.; Liu, J. Effect of Harvesting Time and Moisture Content on Energy Consumption of Compressing Switchgrass. Am. J. Plant Sci. 2014, 5, 3241-3249. [CrossRef]

30. Talebi, S.; Tabil, L.; Opoku, A.; Shaw, M. Compression and relaxation properties of timothy hay. Int. J. Agric. Biol. Eng. 2011, 4, 69-78. [CrossRef]

31. Guo, L.; Wang, D.; Tabil, L.G.; Wang, G. Compression and relaxation properties of selected biomass for briquetting. Biosyst. Eng. 2016, 148, 101-110. [CrossRef]

32. Faborode, M.O.; Callaghan, J.R.O. A rheological model for the compaction of fibrous agricultural materials. J. Agric. Eng. Res. 1989, 42, 165-178. [CrossRef]

33. Stelte, W.; Holm, J.K.; Sanadi, A.R.; Barsberg, S.; Ahrenfeldt, J.; Henriksen, U.B. Fuel pellets from biomass: The importance of the pelletizing pressure and its dependency on the processing conditions. Fuel 2011, 90, 3285-3290. [CrossRef] 
34. Lei, J.L.; Wang, D.F.; Zhang, Q.C.; Yang, X.; Li, L.Q.; Li, C. Experiment on stress relaxation characteristics of intact rice straw during rotary compression. Trans. Chin. Soc. Agric. Eng. 2016, 32, 88-94. [CrossRef]

35. Wang, C.G. Stress Relaxation Time of Hay and Its Application. Trans. Chin. Soc. Agric. Mach. 2007, 38, 65-67. [CrossRef]

36. Yang, M.S.; Du, J.M.; Li, X.Y.; Yang, G.H. An Experimental Study of Fresh Herbage Material Stress Relaxation in the Process of Compression. J. Agric. Mech. Res. 2006, 2, 100-103. [CrossRef]

37. Perrino, E.V.; Wagensommer, R.P. Crop Wild Relatives (CWR) Priority in Italy: Distribution, Ecology, In Situ and Ex Situ Conservation and Expected Actions. Sustainability 2021, 13, 1682. [CrossRef]

38. Chen, T.G.; Zhang, H.W.; Wang, L.; Zhang, L.C.; Wang, J.; Li, J.X.; Gu, Y.Q. Optimization and experiments of picking head transmission system of horizontal spindle type cotton picker. Trans. Chin. Soc. Agric. Eng. 2020, 36, 18-26. [CrossRef]

39. Zhang, L.C.; Zhang, H.W.; Wang, L.; Fu, X.Q.; Chen, T.G.; Wang, J.; Gu, Y.Q. Influence of different boll shell physical parameters on mechanical properties of machine-harvested cottons. Trans. Chin. Soc. Agric. Eng. 2020, 36, 30-37. [CrossRef]

40. Li, Y.; Zhang, H.W.; Yang, T. Batt and fibber's detaching force during cotton harvest-time. J. Shihezi Univ. Nat. Sci. 2011, 29, 633-636. [CrossRef]

41. Du, X.X.; Guo, W.B.; Wang, C.G.; Wang, H.B.; Jin, M.; Liu, X.D.; Li, J. Stress relaxation characteristics and parameters optimization of feed sweet sorghum. J. China Agric. Univ. 2019, 24, 123-131. [CrossRef]

42. Sheng, K.C.; Qian, X.Q.; Wu, J. Experimental studies on compressing chopped cotton stalks to high densities. J. Zhejiang Univ. Agric. Life Sci. 2003, 29, 139-142. [CrossRef]

43. Lehtikangas, P. Storage effects on pelletised sawdust, logging residues and bark. Biomass Bioenergy 2000, 19, 287-293. [CrossRef]

44. Tian, L.; Ji, C.; Chen, X.G.; Wu, J. Parameter optimization of compression moulding of farmland residue film. J. China Agric. Univ. 2019, 24, 139-146. [CrossRef]

45. Li, X.Y.; Yang, M.S.; Lu, G.C.; Kang, W.B.; Ding, H.Q. Transfer rule of compression and springback stress in compression process of alfalfa. Trans. Chin. Soc. Agric. Eng. 2014, 16, 61-67. [CrossRef]

46. Wang, C.G.; Tan, L.D. Study on a Virtual Prototype Based Hay Highly Compressing Process. Trans. Chin. Soc. Agric. Mach. 2005, 36, 99-101. [CrossRef]

47. Guo, W.B. Study on Correlation between the Starch Content of Potato and Its Mechanical Rheological Characteristics. Ph.D. Thesis, Inner Mongolia Agricultural University, Hohhot, China, June 2009.

48. Xie, J.H.; Zhang, X.K.; Zhang, F.W.; Zhang, T.; Dai, F.; Song, X.F. Stress Relaxation Properties Test and Virtual Prototype Simulation for Fresh Jujube. J. China Agric. Univ. 2017, 22, 144-150. [CrossRef] 